\title{
MONOLINGUALISM AND CREATIVITY SCIENTIFIC DISCOURSE AND LINGUISTIC DIVERSITY IN HUMAN AND SOCIAL SCIENCES
}

\author{
DOMINIQUE MAINGUENEAU
}

\begin{abstract}
Whether or not monolingualism - academic English, in practice - is favourable for the production of knowledge in human and social sciences is now called into question. In order to further their careers, researchers seek to publicise their work by publishing in the most prestigious, best-known international journals. But we must not ignore the limits set by the operation of these journals on the production of innovative knowledge to challenge our intellectual routines. We can support the idea that creativity in social and human sciences benefits more from preserving a plurality of scientific production spaces than from a single homogeneous space, which usually tends to fall into complacency.
\end{abstract}

Keywords: scientific journals, monolingualism, human and social sciences, academic English.

To speak of «scientific rhetoric» is to emphasise the resources activated by a researcher so the recipient will share his or her point of view. Among those resources, there is an evident one we tend to forget: the natural language it uses. The problem, nonetheless, presents itself differently for hard sciences and for human and social sciences.

For the first there is a sort of consensus regarding the objectives and procedures of research activity and, therefore, competence is established among individuals, who are subjected to the same set of rules. Regarding human and social sciences, the activity is carried out by groups who disagree on the legitimacy of goals and procedures and who, therefore, do not play exactly by the same rules. We will now consider the latter case.

When we reflect upon the languages used by researchers, we tend naturally to ask ourselves whether or not monolingualism favours the production of knowledge. We do not try to argue in defence of language diversity, as though it were an animal species in need of protection. The idea that researchers should write in their mother tongue because that is the language of their country shows an ignorance of sociolinguistic reality. In the second century AD, a philosopher of Lyon could not have written in Gaulish, despite the fact that Latin and Greek were foreign languages for him; in the twenty-first century, economists will not publish in Slovak, even if that is their mother tongue.

Having several languages is, in principle, an obstacle for science. Therefore, would the most immediate remedy be to have everyone use the same language? It would seem so, and the natural candidate for that role in the contemporary world is academic English, as long, of course, as the scientific community carefully controls its use and watches over the clarity of expression, the accuracy of definitions, the rigour of reasoning and methodology and the respect for bibliographic standards.

PRODUCTION AND CIRCULATION OF SCIENTIFIC DISCOURSE

Actually, reasoning in terms of «language» cannot be avoided; we have to consider the effective conditions 


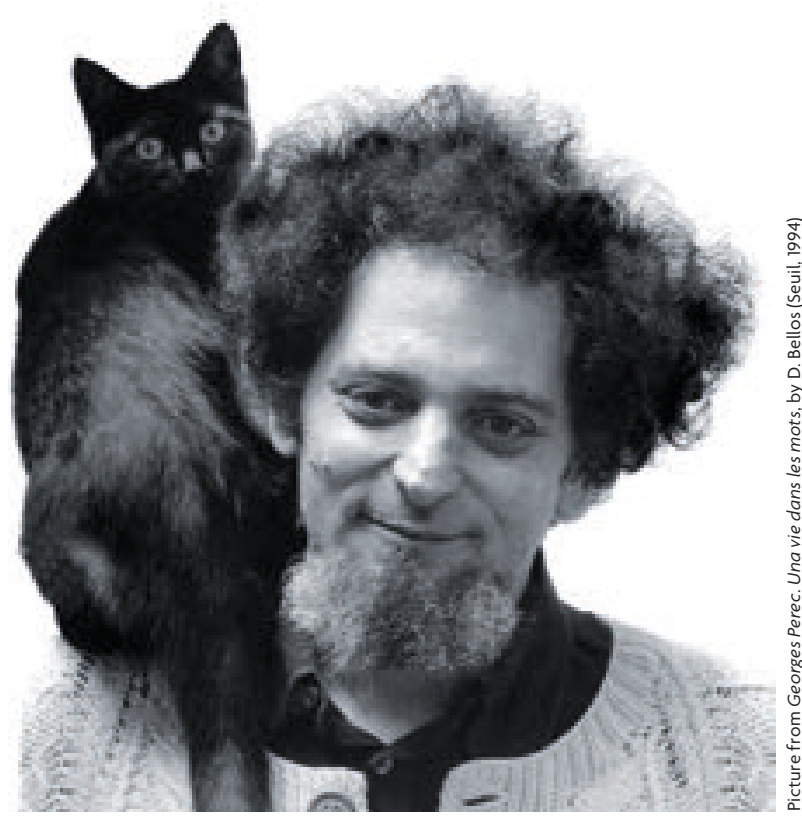

The French writer Georges Perec (1936-1982) published in 1974 a parody of a scientific paper written in English, "Experimental demonstration of the tomatopic organization in the soprano (Cantatrix sopranica L.)". The subject of the paper is absurd (the study of the reaction of a singer when pelted with tomatoes), but it scrupulously respects every rule for the submission of experimental science papers.

for the production and circulation of knowledge «discourses».

Researchers only exist within communities that legitimise them, that validate their statements; these communities are associated with different kinds of discourse; oral (seminars, symposia, conferences, debates...) or written (dissertations, research projects, manuals, collective works, journals, posters...). Within this vast repertoire, the most important discursive genre is, surely, the journal. Scientific journals, strictly hierarchical, are the essential providers of academic authority. The maxim «publish or perish» refers to scientific journals, where the researcher's career is built: contracts, professional category, prestige. This model completely dominates the hard sciences, and is now in the process of conquering human and social sciences. We will, therefore, focus our attention on them.

International journals that are not associated with a particular school or country are the most prestigious; thanks to these publications, despite their diversity, a field of knowledge can display its identity, although competition is clearly greater. Let us imagine that the most prestigious journals are all transnational and Anglophone. Their audience is composed of individuals with very different religious and ethnic affiliations and from very diverse intellectual traditions. Logically, the readers do not usually share a cultural background beyond globalised expertise. Since these journals are the ones that offer the most symbolic benefit, they are also subjected to the strongest control. Those who submit a paper are in a weak position if they try to deviate from the dominant rules or assumptions of the community. What they write must match the expectations of the reviewers who will evaluate their text. Yet they can be from any country or research school, so authors must anticipate the review process, adapting in advance to the dominant customs and predominant criteria in previous issues of the journal. Meanwhile, evaluators must adapt to the image they have as a globalised reviewer. This is how they expect to legitimise their status as experts.

As a result of these factors, the authors of papers adopt some anticipated defence strategies. Particularly: $a$ ) Introducing as many references as possible to the most internationally cited authors in a given discipline. By using these recognised authority references, the authors legitimise their belonging to

a particular field of knowledge.

b) Removing every reference to cultural heritage not shared by a globalised reader. Philosophy, for instance, is not excluded from an international journal on human and social sciences, but authors prefer citations to recent thinkers who write in English: Austin, Grice, Searle, Wittgenstein... rather than Hegel, Husserl or Bergson. c) Avoiding deviation from the most common stylistic rules in the discipline: from lexical to compositional aspects. Scientific texts use a particularly restricted repertoire in terms of vocabulary and syntax, making it easier for authors who are not native English speakers.

The power gap between the would-be publisher and the journal is widened by the fact that most writers' mother tongue is not English, so they turn necessity into virtue: when one is not a native speaker it is in one's interest not to risk being rejected.

Logically, a dynamic such as this tends more towards the impoverishment of scientific creation than to originality, more to consensus than to discrepancy, given the fact that the papers that produce less original content have more possibilities of being published without much hassle.

The French writer Georges Perec (1936-1982) published in 1974 a scientific paper parody written in English: «Experimental demonstration of the 
tomatopic organization in the soprano (Cantatrix sopranica $L$.)». The subject of the paper is absurd (the study of the reaction of a singer when pelted with tomatoes), but it scrupulously respects every rule for the submission of experimental science papers. Here is the beginning:

As observed at the turn of the century by Marks \& Spencer (1899), who first named the «yelling reaction» (YR), the striking effects of tomato throwing on Sopranoes have been extensively described. Although numerous behavioral (Zeeg \& Puss, 1931; Roux \& Combaluzier, 1932; Sinon et al., 1948), pathological (Hun \& Deu, 1960), comparative (Karybb \& Szyla, 1973) and follow-up (Else \& Vire, 1974) studies have permitted a valuable description of these typical responses, neuroanatomical, as well as neurophysiological data, are, in spite of their number, surprisingly confusing. In their henceforth late twenties' classical demonstrations, Chou \& Lai (1927 a, b, c, 1928 a, b, 1929 a, 1930) have ruled out the hypothesis of a pure facio-facial nociceptive reflex that has been advanced for many years by a number of authors (Mace \& Doyne, 1912; Payre \& Tairnelle, 1916; Sornette \& Billevayzé, 1925).

(Perec, 1991, p. 13)

Reading this text makes us realise that the meticulous respect for the rules of this discursive genre, associated with the dominance of scientific English, is enough to confer strong authority and veracity to the document. Luckily, the author, as in other parodies, embellishes

the text with comical bibliographic references ( $« \mathrm{Chou}$ et Lai» the name of a Chinese politician, «Payre et Tairnelle», homonymous of "Eternal Father" in French...) to remind the reader that it was all just nonsense.

The parody inevitably reminds us of the famous «Sokal affair»: the physicist Alan Sokal managed to publish a nonsensical paper titled «Transgressing the Boundaries:

Toward a Transformative Hermeneutics of Quantum Gravity» (Sokal, 1996) in a prestigious American journal, Social Text. The content of the paper was, indeed, pure absurdity, but adhered to the style criteria of the journal. Sokal put the hoax in motion in order to ridicule postmodern thinkers. But we could also learn the lesson that adhering to the usual rules of a discursive community is enough to be convincing, regardless of quality.

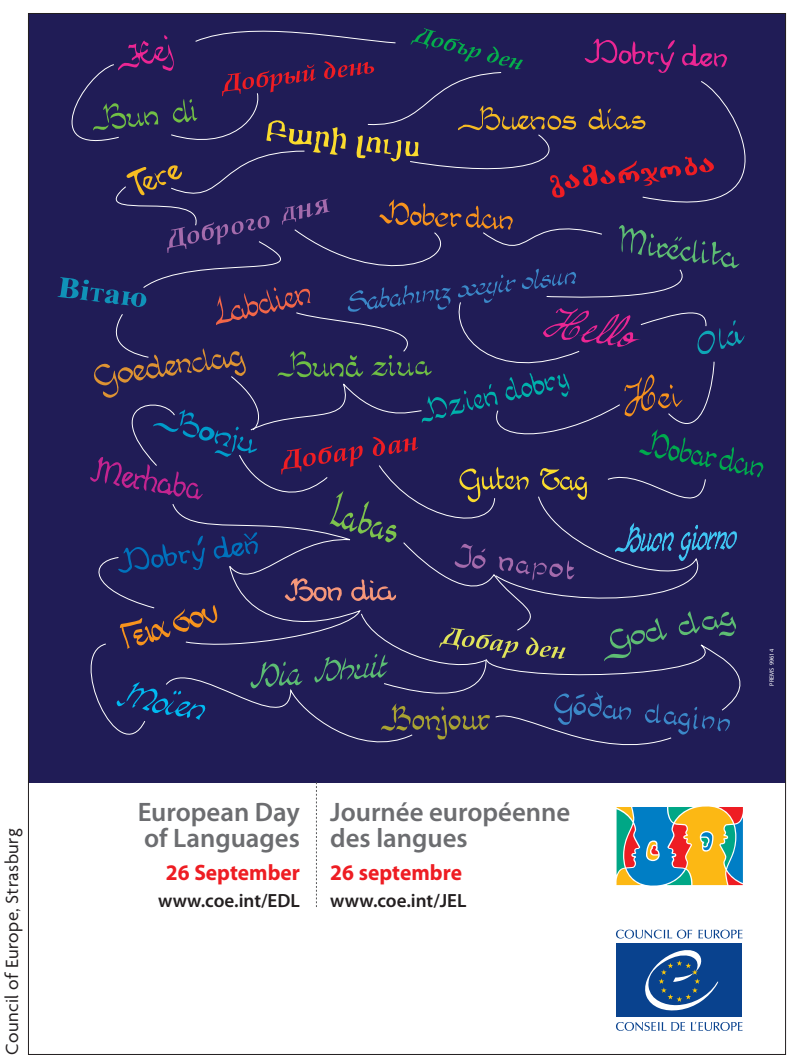

If we do not preserve a variety of linguistic circulation and evaluation spaces, we run the risk of reaching a situation we could categorise as academic diglossia, which is unfavourable for the creation of knowledge. In the picture, poster for the European Day of Languages, celebrated on 26 September.

\section{"THE DYNAMIC OF THE SCIENTIFIC JOURNALS TENDS MORE TOWARDS THE IMPOVERISHMENT OF SCIENTIFIC CREATION THAN TO ORIGINALITY, MORE TO CONSENSUS THAN TO DISCREPANCY»}

DANGERS OF A GLOBALISED SPACE

In a globalised monolingual space for the production and circulation of texts, the main specialists of a discipline write in the same journals, are members of the same honorary or advisory boards, participate in the same conferences, in the same international seminars, etc. Some attitudes, such as a natural fellow feeling, make them pay little attention to theoretical conflicts. The values of community integration predominate and the debates are minor issues.

However, research quality is constantly threatened by two opposing dangers. The first, most visible, is sectarianism; the second, which is not highlighted as often but is also real, is consensus, which progressively imposes routines on research: 
researchers are (more and more as time passes) professionals who do their job and avoid challenging dominant assumptions.

The ability to transcend particularisms is not necessarily a factor for intellectual creation. If that were the case, then the Netherlands or Belgium - in contact with German, English and French traditions - or Latin American countries - in contact simultaneously with the USA and Europe - would be the most creative countries. Actually, it would be better to accept that there is no contradiction in human and social sciences between the local character of the production of knowledge and its vocation to universality. If we want to erase any ascription to prereflexive experience, located geographically and historically, the production of knowledge risks becoming a matter of institutions that validate themselves based on following routines.

From this point of view, we can think that the existence of a plurality of languages for scientific communication, partnered with broad circulation spaces, can be positive. The readers of globalised journals are, by nature, different from those we might call «idiomatic» (that is, those that are associated with a language or group of languages, such as Scandinavian or Romance languages). In the case of «idiomatic» readers, the common cultural background gains importance. The writers know they are writing for a readership who not only work in the same discipline, but share many cultural references and a number of epistemological assumptions with them. The circulation space of the journal is more restricted, so an author can impose their individuality more easily. In this relatively protected market, it is not necessary to constantly offer evidence of the right to publish a paper adapted to the lowest common denominator of a global audience. This diversity also favours a more intimate relationship with language, which is always important for conceptual work in human and social sciences or philosophy. It also helps to open the discipline to currents other than the dominant international ones.

If we do not preserve a variety of spaces of linguistic circulation and evaluation, we run the risk of reaching a situation we could categorise as academic diglossia, which is unfavourable for the creation of knowledge; there will be, on the one
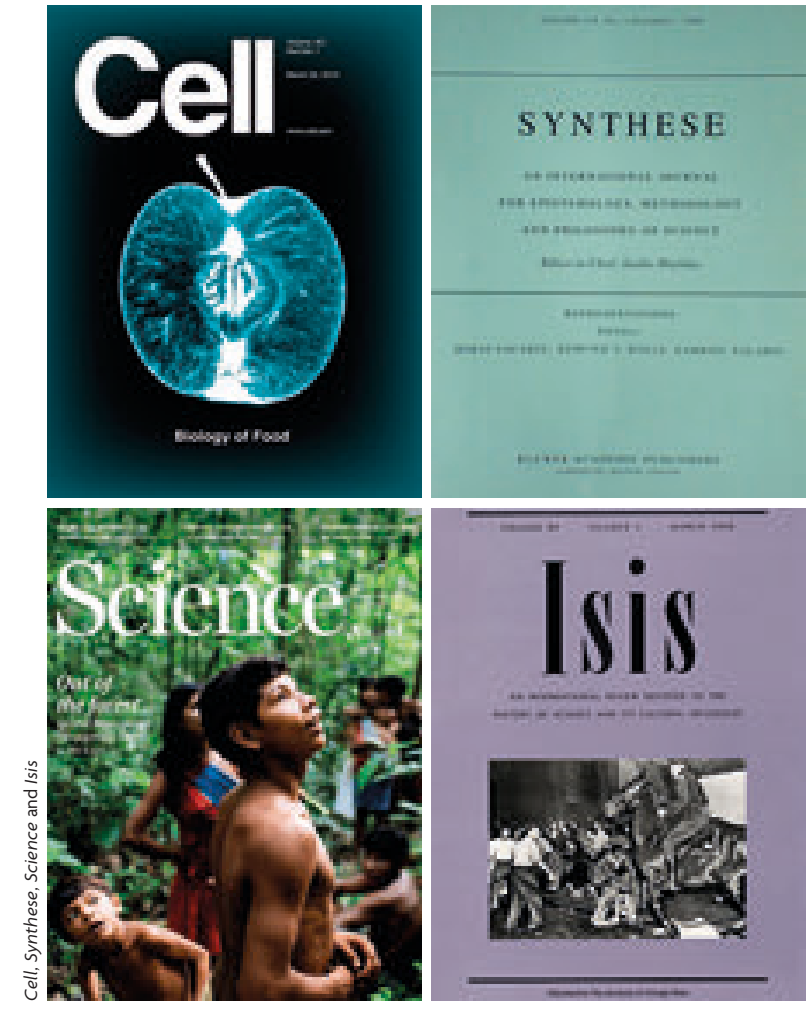

hand, international Englishlanguage publications, unoriginal prestige sources; and on the other, documents published in dozens of vernacular languages, «local» texts, less prestigious and with different levels of quality. Paradoxically, conformity will prevail in globalised journals, the ones people read, which are an authoritative voice, not so much due to the will of the publications administrators -who are looking for the opposite result- but due to the internal logic of the entity.

\section{LANGUAGE FOR THE PRODUCTION AND TRANSMISSION OF KNOWLEDGE}

We should, therefore, not confuse the language of production with the language of transmission. It is not a matter of rejecting English as the dominant language for the worldwide circulation of knowledge, but of combating the idea that widespread monolingualism would favour, by definition, the creation of knowledge. The important thing is to preserve the traditions that lie beyond the alternatives of global and local. Here, «global» refers to inquiries 


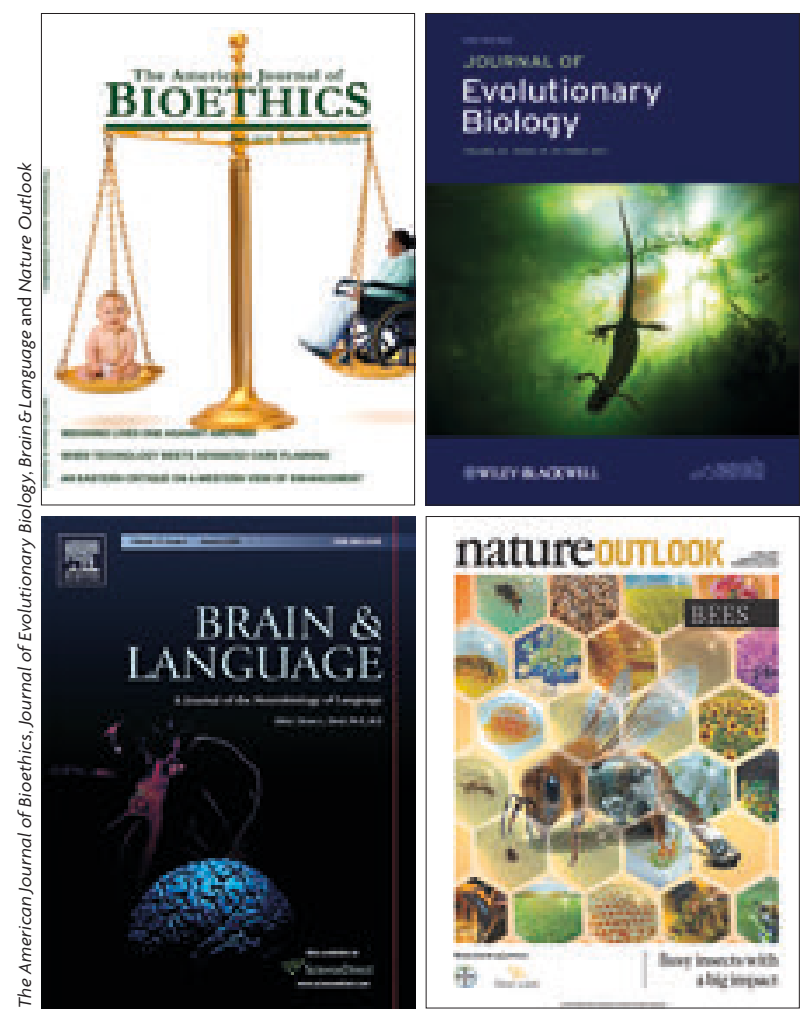

The power gap between the would-be publisher and the journal is widened by the fact that most writers' mother tongue is not English, so they turn necessity into virtue: when one is not a native speaker it is in one's interest not to risk being rejected. Above, covers from different scientific journals.

adapted to worldwide dominant assumptions that favour the careers of researchers, eager to feel part of a globalised community. «Local» refers to marginalized currents, schools or territories (national or regional spaces, as well as a university or a university department), without dissemination or prestige, which develop within the cosy space of a group withdrawn into its concepts and values.

Regarding the Internet, these traditions cannot be circumscribed to a compact national or multinational space, and they are stronger when they can join a related language or group of languages. Furthermore, far from imprisoning them in a space, it allows researchers to participate in different spaces, with every imaginable form of hybridization: British researchers share the English language with the USA, but at the same time they are European; Argentinian researchers share the Spanish language with
Spaniards but they are also South American. French researchers are at the same time in the international French-speaking sphere and in the sphere of Romance languages, in a European space and, obviously, a French space. Linguistic diversity does not do justice to this diversity, but it helps to preserve it.

We may, however, ask ourselves if the term tradition is well suited. It seems to be a homogeneous set linked to national roots and to a language; in addition, it favours a relationship with the past to the detriment of synchronic interactions. Rather than «traditions», we should talk about «confrontation spaces», a notion that certainly implies a frontier with the external space, but also internal frontiers, the existence of different stances at the core of the same space. Due to their diversity, these confrontation spaces make the theoretical assumptions upon which each is based clearly visible. If we adopt this perspective, we are tempted to dissociate prestige and monolingualism. Particularly, this means that interests favour the emergence of prestigious journals in different languages, instead of directly associating prestige with the English language. Thus, we must not confuse the language of production with the language for the dissemination of knowledge. It is common for English, as the dominant language for international exchanges, to be used to disseminate the content of human and social sciences. It is not so clear or evident that its use necessarily guarantees the quality of knowledge production.

Indeed, there is something disturbing in favouring conflict, but it is a necessary condition for intellectual innovation, which is the ultimate goal of research. Researchers work not only to produce knowledge, but to preserve the conditions that allow the production of knowledge adapted to scientific ethics. (-)

\author{
REFERENCES \\ Perec, G. (1991). Cantatix sopranica L. et autres écrits scientifiques. Paris: \\ Seuil. \\ Sokal, A. (1996). Transgressing the boundaries: Towards a transformative \\ hermeneutics of quantum gravity. Social Text, 46/47, 217-252. doi: \\ $10.2307 / 466856$
}

Dominique Maingueneau. Full Professor of Language Science of the Paris-Sorbonne University (France). For decades, his research has focused on French linguistics and discourse analysis. Some of his most recent books are Discours et analyse du discours (Armand Colin, 2014) and, together with J. Angermuller and R. Wodak, The discourse studies reader. Main trends in theory and analysis (John Benjamins, 2014). 